\title{
External Forces Shaping the Future of the Insurance Industry
}

\author{
Gregory V. Serio
}

Park Strategies, LLC, 101, Park Avenue, New York, NY 10178, U.S.A.

E-mail: gserio@parkstrategies.com

The insurance industry is facing a number of serious issues from external forces, not the least of which has been a significant increase in regulatory and enforcement actions by American and international authorities. These forces have worked to compound challenges already confronting insurers in the underwriting, rating and claims settlement areas. However, it can be theorized that the external forces facing the industry are directly correlative to the internal issues as (1) these internal issues, especially in the areas of natural catastrophes, terrorism and risk management, are really reflective of the challenges facing governments, businesses and the public, (2) those sectors are coming to rely upon insurers more and more to address those issues, and (3) the insurance industry will not be able to meet those challenges facing its various constituencies without being at peak operational, financial and ethical effectiveness and efficiency, which is why it is critical to focus on addressing those external forces.

The Geneva Papers (2006) 31, 31-37. doi:10.1057/palgrave.gpp.2510065

Keywords: supervision and regulation; external and internal forces; insurance industry

The decision of the General Assembly of The Geneva Association to concentrate a part of its recent Annual Meeting on the external forces influencing the insurance industry today offers great hope for the future of the business of insurance. The fact that the chief executives of the largest global companies in this important enterprise have chosen to look beyond the four corners of the once-insular world of insurance to critically evaluate the impact of these outside forces on the industry's practices assures us that the future of insurance will undoubtedly be better than its past. The fact that so many within the industry are looking for responsible leadership to see it through the current travails - those we know about and those that we will come to know about will help the CEO community find an eager workforce ready to make the changes necessary to insurance, how it is practiced and how it is perceived. The leaders of the industry will also find a public that is both eager for modernization of the governance of the industry and concerned that such reforms will only be the yield of a tumultuous upheaval as seen in other financial sectors.

Undoubtedly, and appropriately, the first concept to strike the informed mind in insurance when thinking about the external forces affecting it is the new regulatory environment in which the industry now finds itself. Regulatory and specifically enforcement issues still dominate the headlines in the trade and business news media, and each day continues to bring more unsettling accusations of wrongdoing within various corners of the business. Regulators and prosecutors are clearly highly motivated and focused on rooting out wrongdoing and inappropriate behaviour. Industry attempts to minimize the problem or explain it away have been largely 
ineffective counterweights to the legal tour de force that we have seen over the past year. As misguided as some of those efforts have been, even more poorly conceived attacks focused directly on those prosecutors and regulators who have brought some of these practices to light have only emboldened officials who apparently have no shortage of bad news to share with this industry.

Enforcement actions on commissions, finite reinsurance and accounting practices against both brokers and underwriters, together with the frustrations of a meandering policy discussion in the United States concerning the appropriate level of government for regulating the business of insurance that has yielded little in the way of consensus, have allowed the external factors to seemingly overwhelm an industry that is already reeling from a number of major catastrophes and other major business issues. The property/casualty insurance community, for example, has failed in the United States to respond to Congressional entreaties of the past several years to develop a private market terrorism risk mechanism, and is now expressing deep concern over the prospect that the Terrorism Risk Insurance Act will expire while at the same time protecting its own flanks by increasing premiums and closing down coverage options for business, earning the scorn of business policyholders from coast to coast. This course of action will only invite even greater regulatory attention and a new round of recriminations focused squarely at an industry that already has spent more than its share of time under the white hot lights of public scrutiny. Worse still, others, motivated by self-interest and instigated by the apparent policy confusion in the market, have taken sweeping and definitive actions like eliminating contingent compensation arrangements in the name of reform - even though no regulator has declared the practice of paying contingent commissions to be illegal - only to be, yet again, tone deaf to the pleas of the consumer who was disenfranchised in the first place. The result: higher prices to commission-paying buyers who are now being asked to make up the shortfalls in broker income from the elimination of the contingent payments and fees being charged by brokers to insurers. If an objection has been voiced from any corner of the market, it has been muted.

There has yet to emerge from the ranks of the global insurance leadership, before today, a coordinated effort to create an opportunity out of the adversity that so many of these external forces have come to represent for the industry. By championing a meaningful self-regulatory process and mechanism which, when combined with a newly invigorated governmental regulatory system understandably agitated by the realities of players making patently false and misleading misrepresentations in financial and accounting filings (among other transgressions), the insurance industry itself will help root out and, ultimately, prevent these activities from happening in the first place. The American life insurance industry did such a thing about 10 years ago when it created the Insurance Marketplace Standards Association (IMSA). Born of the retirement products marketing scandals of the early 1990s, IMSA, together with the development of effective compliance units within some carriers, has come to represent a beachhead in the industry's effort to take responsibility for its actions. After several changes to its processes as it moved from its nascent stages to a more evolved state, IMSA is now providing meaningful self-regulatory discipline for that sector and achieving practical interfacing with regulatory processes, bringing value and efficiency to both regulators and companies in the process. New York, Texas and 
Massachussetts, for example, within the last 2 years have incorporated IMSA work products into their market conduct examination protocols. By assuring full transparency of process, disclosure of Association standards and IMSA examiner qualifications and work papers, the industry has given the regulatory community a viable tool to assist it in the oversight of the industry. Such a mechanism would go far to bring the commitment of best practices to an institutional level not currently present in the property/casualty market and help spur the development of important compliance practices within many companies that currently do not engage them.

The creation of and support for a self-regulatory mechanism necessarily brings a more universal issue into sharper focus: the adoption of broader, generally accepted corporate governance standards by the insurance industry on a uniform and global basis. Insurance, characterized by its unique regulatory structure, including two methods of accounting, its corporate structures divided among public, mutual and not-for-profit entities, and its tradition-steeped practices, has been slow to adopt corporate governance principles now in place in other financial services sectors. Unlike the efforts of a few years ago to eliminate statutory accounting in favour of GAAP accounting as a method of integrating insurance into the larger universe of financial services - an initiative that actually would have made insurance regulation weaker the adoption of established corporate governance, internal control and ethics rules that are self-imposed upon the industry would be far more effective than the current practice of gauging the efficacy of corporate governance in insurance simply by the regulatory actions taken.

The government's concentrated effort to expose wrongdoing in insurance and to promote corporate governance best practices is not merely an attempt to notch another victory in the fight against corporate crime. Rather, it is the recognition that an industry that is relied upon by both governments and private parties for essential economic protection needs to be operating at peak ethical, as well as operational and financial, efficiency and effectiveness so that the public may put all its faith in the efficacy of the security that insurance provides. Even more so, government is relying on insurance more than ever before to cover risks, for natural disasters, terrorism, financial risk and other exposures that were not envisioned just a few years ago. And, in the recent push by the federal government of the United States to encourage greater disaster preparedness among private entities, the Congress has singled out the insurance industry (along with credit rating agencies) as one of the most effective mechanisms for promoting disaster preparedness regimens in businesses.

In the months after September 11, the United States Treasury, the Federal Reserve and other financial regulators came to understand, some for the first time, the crucial role that insurance plays in the marketplace. Mapping the insurance process, overlaying it upon the monetary system and other models utilized to diagram the various operating systems comprising the economy, and conducting vulnerability assessments for insurance alongside similar exercises for other financial services sectors illustrated the point that insurance, although regulated by the states, is critical to the national and global economies. The reservoir of goodwill derived from the industry's responsible approach to $9 / 11$ claims management, including the payout of over $\$ 30$ billion, was now buttressed by actual analytical support as to the critical role that insurance plays. 
Since then, and specifically within the Intelligence Reform and Terrorism Prevention Act of 2004 enacted by the Congress and signed by President George W. Bush in December, 2004, the insurance industry has been given a tremendous opportunity and a crucial role in the private sector preparedness initiative that has come from the whole $9 / 11$ experience. New standards for private company readiness created by the National Fire Protection Association with significant insurance industry input were given the imprimatur of the federal government in The 9/11 Commission Report and legislation. Section 7305 of the Act provides that "recognizing that private sector organizations own 85 percent of the Nation's critical infrastructure and employ the vast majority of the Nation's workers... [i]t is the sense of the Congress that the secretary of Homeland Security should promote, where appropriate, the adoption of voluntary national preparedness standards such as the private sector preparedness standard...based on the National Fire Protection Association 1600 Standard on Disaster/Emergency Management and Business Continuity Programs." 1 For the first time, the Congress was instructing a government agency to affirmatively encourage the development of preparedness programs as a matter of good public policy and sound citizenship, helping to mitigate, for both government and insurers, the risk of loss from emergencies.

The connection between private sector preparedness and the insurance industry was made even clearer when further on in the Act, the Congress directly mentioned the insurance industry as a catalyst for implementation of these standards through the underwriting process:

Sec. 7804. Private Sector Preparedness

It is the sense of the Congress that the insurance industry... where relevant, should carefully consider a company's compliance with standards for private sector disaster and emergency preparedness in assessing insurability ... to ensure that private sector investment in disaster and emergency preparedness is appropriately encouraged. ${ }^{2}$

This provides the industry with a powerful new underwriting and rating tool (certainly a rationale) in its relationship with customers, but also a delicate responsibility that it carry out the public objective of greater preparedness in a fair and objective manner. Only an industry that has the full confidence of government and the public can meet these demands.

Another external force certain to shape the future of the insurance industry, and directly related to the issue of risk management and preparedness, is the changing face of the insurance buyer. Here, traditional notions of the buyer-broker-carrier relationships are being recast, both from realities of the marketplace, as noted above, the increasing sophistication of the commercial insured and the recent regulatory actions, particularly those involving contingent compensation arrangements. The concept of enterprise risk management in business is being buttressed by a trend

\footnotetext{
${ }^{1}$ Intelligence Reform and Terrorism Prevention Act (2004).

${ }^{2}$ Ibid.
} 
toward the appointment of chief risk officers in corporations to actually undertake the enterprise risk management task. And more corporate officers and directors, in a new "top-down" approach to risk management, are not only understanding the crucial role that risk control plays in operational and financial terms, but they are gaining a new appreciation for the synergistic relationship between risk strategy and larger corporate strategy. The adoption of the chief risk officer concept is allowing those synergies to be explored more productively.

The trends towards self-insurance and alternative risk financing mechanisms are helping to propel this change in risk management and corporate culture. The range of options for risk financing available to chief risk officers and risk managers is the widest it has ever been. While some traditional carriers and brokers may take solace in the flat trendliness in the overall use of self-insurance mechanisms over the past year, the growth of captives and other ARTs and the increasing of capacity or the adding of lines to establish captives illustrate to the industry that the usual trends of the past are not being replicated now.

Indeed, the conventional schools of thought that soft markets and stabilized prices bring lethargy among risk managers who calculate their responsibilities only in terms of available coverages and prices are being challenged by a small but increasingly vocal segment of the risk management community that is insisting that risk management does not, and certainly should not, ebb and flow with the insurance market's cycles. Today's satisfaction that self-insurance has not gained any greater strength will quickly give way when the risk management discipline transforms into an aggressive and robust component of corporate strategy and operations for buyers; when alternative forms of risk financing are routinely evaluated; when new demands for better and more flexible coverages and financing of coverages are made of carriers and brokers; and when enterprise risk management is handed over to chief risk officers sitting several levels above today's risk manager, on par with the chief financial and legal officers and interacting directly with chief executive officers and board members.

Most critically, this transformation will be highlighted by the risk management professional taking control - in many instances for the first time - of the relationship with carriers and brokers. It may well be the broker community that ultimately loses out as CROs, with newfound authority and autonomy, find they can more efficiently and effectively build multi-faceted insurance programmes comprising traditional and alternative risk transfer methodologies (with captives, securitization and other facility and financing options) directly with carriers or other financial partners and managed within their own risk management organizations.

In a white paper on the role of the insurance broker released in September 2005, the International Federation of Risk and Insurance Management Associations (IFRIMA) did its part to further the discussion on the evolving role of the risk manager and the interplay with brokers and carriers when it observed:

Many insurance brokers describe their role as purchasing the most coverage possible at the lowest price. This is not necessarily true. The role of the broker is to execute the insurance management strategy that is determined by its client, to the extent indicated by the client. For most organizations, that strategy will include the development of strong, long-term relationships with its insurance 
transfer partners...(including) personal and corporate relationships with the underwriters on his or her account... It is up to the risk manager to determine the risk financing strategy and then to direct the efforts relating to the presentation of the risk and the negotiation of the terms of the insurance policies. ${ }^{3}$

In fact, IFRIMA, in a June 2004 position paper, gave an even broader view of the evolving risk management officer role when it detailed three critical areas of activity for enterprise risk managers, including:

- understanding the overall business objectives of the organization and leveraging where available risk management techniques to further the corporate objective;

- establishing a consistent and transparent framework for corporate governance, including the approval of risk management programs by corporate boards, and reporting pro-active risk management and prevention initiatives to shareholders and regulators; and

- understanding all internal and external risks to the enterprise and assuring adequate risk transfer, be it through insurance, hedging and other financial alternatives. ${ }^{4}$

To be sure, the predictable patterns of behaviour - hard markets bring higher deductibles, increased loss control and tighter coverage terms, while soft markets reduce the emphasis on loss control, deductibles become more pliable and coverages seem to take on again a certain elasticity, then back to hard markets and so on - will be challenged mightily by those who seek the veritable holy grail of insurance (and the one thing that makes risk managers, senior corporate officers and board members sleep well at night), that is, stability. If the traditional insurance marketplace cannot better assure stability of pricing and availability of coverages through all insurance or economic cycles, then it becomes fair game for risk managers and newly empowered and more sophisticated risk officers, to go elsewhere to find it.

It is the erstwhile risk manager who will not be lulled into blissful and false serenity with the onset of the soft market but who goes to work using the relative calm of the soft market to build the stabilizing programs necessary to make certain that his client is not upended again by the next cyclical change of the insurance market. Whether woken up by the disruption of the last hard market, the antagonism of the broker compensation scandal, or simply by the pursuit of a higher degree of excellent in their craft, there are many more risk managers today exploring alternatives than there were during the last cyclical change.

It makes sense that as chief risk officers and risk managers are asked to cover a wider variety of risk they seek a wider array of coverage options, many of which are not now effectively provided by the traditional insurance marketplace. According to recent research by The Economist, 52 per cent of European and American executives surveyed indicated an intention to expand the breadth of risk management responsibilities, and 24 per cent of those surveyed expected to appoint chief risk officers within the next 2 years as one way to accomplish this objective. Particularly for

\footnotetext{
${ }^{3}$ IFRIMA (2005).

${ }^{4}$ IFRIMA (2004).
} 
non-financial firms that see as their biggest risk challenge managing multi-faceted risks on a global basis, the availability of a wider array of risk financing techniques that easily glide across multiple jurisdictional boundaries will be crucial. Interestingly, this research was sponsored by, among others, a major global insurer no doubt anticipating that the evolving role of the risk manager will be one external force shaping the future of insurance.

\section{References}

IFRIMA (2005) Role of the insurance broker, White Paper, September 2005.

IFRIMA (2004) Enterprise risk management, Position Paper, June 2004.

Intelligence Reform and Terrorism Prevention Act (2004) Conference Report, S.2845, Government Printing Office, Washington, DC.

\section{About the Author}

Gregory V. Serio is the Managing Director of the New York City-based Park Strategies and leader of its risk and insurance management practice group. He is the former Superintendent of Insurance, State of New York. 